\title{
Arqueoastronomía en el arte rupestre de Valle y Choluteca
}

\author{
Marco Antonio Pineda \\ César Israel Rodriguez Carías
}

\section{Resumen}

Esta investigación denominada Arqueoastronomía en el Arte Rupestre de Choluteca y Valle tenía por objetivo analizar sitios de Arte rupestre en los departamentos de Valle y Choluteca de la zona sur de Honduras, para determinar su posible contenido de información Arqueoastronómica.

La profundidad del estudio implicó describir, registrar y analizar las muestras de Arte Rupestre encontradas en los diferentes sitios y determinar una posible relación astronómica en su diseño. La realización abarco desde el mes de agosto de 2013 a septiembre de 2014. Se trabajó con los sitios arqueológicos que presentaron muestras de Arte Rupestre en el sur de Honduras, específicamente en los departamentos de Choluteca y Valle. La presente investigación es de tipo descriptivo y transversal en la que se realizó una descripción y análisis del entorno general de los sitios, hasta llegar a la descripción y el análisis in situ y fotográfico del Arte Rupestre con características astronómicas, ya sean estos pictóricos o petrograbados. Como resultados del estudio pudimos comprobar la existencia de diseños de Arte Rupestre con posible contenido astronómico en diferentes sitios de los departamentos de Choluteca y Valle. Esta investigación permite llenar vacios de información científica sobre el Arte Rupestre en la zona sur de Honduras. Se aclara que estos son resultados preliminares a la puesta en marcha de un proyecto de investigación innovador en Honduras, donde se pone a prueba la metodología de investigación para el estudio arqueoastronómico en el Arte Rupestre.

Palabras clave: Arqueoastronomía, Arte Rupestre, Astronomía, petroglifos, Pictografía 


\section{Abstract}

His investigation named Arqueoastronomía in the rock Art of Choluteca and Valley had for aim analyze sites of rock Art in the departments of Valley and Choluteca of the south zone of Honduras, to determine his possible content of information Arqueoastronómica. The depth of the study implied describing, registering and analyzing the samples of rock Art found in the different sites and to determine a possible astronomic relation in his design. The accomplishment I include from August, 2013 to September, 2014. One worked with the archaeological sites that presented samples of rock Art in the south of Honduras, specifically in the departments of Choluteca and Valley. The present investigation is of descriptive and transverse type in that there was realized a description and analysis of the general environment of the sites, up to coming to the description and the analysis in situ and photographically of the rock Art with astronomic characteristics, already be these pictorial or petrograbados. Since results of the study we could verify the existence of designs of rock Art with possible astronomic content in different sites of the departments of Choluteca and Valley. This investigation allows to fill emptynesses of scientific information about the rock Art in the south zone of Honduras. It is explained that these are preliminary results to the putting in march of an innovative project of investigation in Honduras, Where the methodology of investigation is tested for the study arqueoastronómico in the rock Art.

Keywords:Archaeoastronomy, Rock Art, Astronomy, petroglyph, pictograph

Marco Antonio Pineda, César Israel Rodriguez Carías, Departamento de Arqueoastronomía y Astronomía Cultural, Universidad Nacional Autónoma de Honduras 


\section{Introducción}

Por medio de este estudio, se identificó la relación de los sitios arqueológicos que se encontraron en los departamentos de Choluteca y Valle, con astros; como ser las observaciones del Sol, la Luna, planetas y estrellas por parte de los antiguos habitantes que plasmaron en la roca su cosmovisión, y así poder reconstruir parte de la historia antigua de los pobladores del sur de Honduras. Con esta investigación se encontró evidencia de estos conocimientos en las muestras de arte rupestre (petroglifos o pintura) existentes en abrigos y otras estructuras geológicas presentes en la zona.

Estas investigaciones son de importancia en el desarrollo de campos científicos como la Arqueoastronomía y la Astronomía Cultural en Honduras y para el desarrollo teórico - práctico, de las asignaturas tecnológico-científico de punta impartidas por la Facultad de Ciencias Espaciales de la Universidad Nacional Autónoma de Honduras. Siendo nuestro país el primero en contar con un Departamento de Arqueoastronomía y Astronomía Cultural a nivel académico superior, y estando la Astronomía Cultural en auge a nivel mundial. Esta investigación refuerza el desarrollo científico de estas nuevas áreas del conocimiento. Con esta investigación, también se apoya la labor del IHAH en pro de la investigación y rescate de nuestro Patrimonio Cultural. Reforzando nuestra identidad nacional y llenando vacíos de información científica en un área hasta ahora poco conocida culturalmente como ser la zona sur de Honduras. Rescatando los conocimientos que nuestros ancestros nos heredaron en piedra. Este es el contexto académico y de protección cultural que ha justificado este proyecto de investigación.

El área de estudio de nuestra investigación corresponde regiones definidas de los departamentos de Choluteca y Valle en el Sur de Honduras, escogidas en base a la ubicación se sitios de Arte Rupestre, obtenidos de revisión bibliográfica, entrevistas y informantes en la zona. Esta área en la Región Sur de Honduras y la planicie costera del litoral Pacífico abarca un total del $2 \%$ del territorio nacional. Tiene una longitud de 133 kms. y la cruzan cuatro ríos, siendo estos, Goascorán, Nacaome, Choluteca y Negro. Pineda, Portillo (1997). Esta planicie costera goza de un clima de sabana, tropical lluvioso y seco, prevalecen dos estaciones bien marcadas: una de sequía (verano) y otra de lluvias (invierno). Las islas (conos) de este golfo son testigo de actividad volcánica antigua. Pineda, Portillo (1997).

Según Martínez C, y Botiva, C. A. (2004). Se conoce como arte rupestre a los rastros de actividad humana o imágenes que han sido grabadas o pintadas sobre superficies rocosas. 
Es muy difícil hacer generalidades sobre las diferentes muestras de arte rupestre, en lo que se coincide es en clasificarlas en dos tipos según Guevara, 2012:

- Petroglifos

- Pintura rupestre.

Los primeros, se trata de grabaciones hechas en la roca, usando un objeto material con características de mayor dureza, que permitiera la abrasión de la roca; es probable que en los casos más recientes, primero se hiciera un dibujo sobre la misma, usando tintes de colores, para luego hacer la escisión siguiendo los trazos definidos previamente. En el segundo caso se trata de dibujos y pinturas realizadas con pigmentos sobre las superficies rocosas.

Se conoce como petroglifo a una imagen que ha sido grabada en la superficies rocosas (del griego petros: piedra y griphein: grabar).y Las pictografías (del latín pictum: relativo a pintar, y del griego grapho: trazar) son grafismos realizados sobre las rocas mediante la aplicación de pigmentos. Martínez Celis, Diego, Botiva Contreras, Álvaro. (2007).

El arte rupestre es el testimonio de la expresión de las relaciones directas entre las manifestaciones y su entorno, y de un pensamiento común procedente de una misma cultura de origen amerindio, Nuria Sanz afirma que entre los lugares intencionales identificados deben mencionarse las cuevas, así como los refugios rocosos y los bloques rocosos, todos los cuales tienen una relación particular con las fuentes de agua. Las técnicas generales de producción son grabados y pinturas, y las representaciones insisten sobre todo en los motivos antropomorfos, zoomorfos y geométricos. Nuria Sanz (2008)

La tarea de establecer el periodo de producción de estos petroglifos y atribuirlos a una u otra fase cultural, población o grupo es sin duda una de las más difíciles en las ciencias antropológicas y arqueológicas; según Guardado (1991).

Según Jaimes (2010). Pudo haber un gran número de razones para que los grupos de humanos decidieran elaborar arte rupestre entre ellas se podría tratar e prácticas rituales $u$ ofrendas, intenciones puramente estéticas o la necesidad y vehículo de comunicar saberes, mitos, etc. Los rituales estarían presididos por chamanes y serían la representación de creencias en seres sobrenaturales, en otros mundos no completamente humanos y en relaciones cósmicas. 
El arqueólogo Fernando López, En Mendiola (2002), expresa: “...la expresión artística impacta de manera directa y cercana al público, mientras que el discurso científico nunca lo hace, si a fin de cuentas, hablan de la misma realidad, aunque percibidas, se dice de distintas maneras." (...) "Quizá la pregunta que surge de inmediato es: ¿cómo "le hicieron" los artistas para encontrar lo que tanto trabajo le costó a los científicos?. De hecho una interrogante análoga se encuentra en lo asombroso que ha sido para los científicos modernos encontrar una sorprendente exactitud y precisión en el conocimiento de muchas sociedades no occidentales lo que ha sido constatado por la Arqueoastronomía, por las investigaciones arqueológicas y etnohistóricas".

Muchos arqueólogos creen que los estudios del paleoarte no tienen relevancia para "la correcta práctica arqueológica" o que sólo pueden tener un uso limitado en la interpretación arqueológica. En realidad las ideas que algunos arqueólogos tienen sobre los propósitos de los estudio del paleoarte parecen absurdas cuando se considera la clase de modelos que tienen en mente. Estos incluyen la identificación iconográfica (p.e. la utilización de su propio proceso cortical por medio del cual se equiparan patrones neurológicos de objetos con la percepción visual gráfica) de objetos supuestamente representados en las obras (tales como herramientas, armas, animales, huellas, etc) los cuales son científicamente insustentables o la determinación "estilística" y otros patrones de distribución percibidos, que son vistos como codificaciones de diversos tipos de información demográfica, simbólica y cultural, por ejemplo: límites tribales, difusión cultural, incluso densidades de población. Bednarik (2004).

Broda (1997), Plantea que un sistema de códigos se plasma en el paisaje. Edificios aislados, conjuntos de edificios y planos de asentamientos de sitios enteros muestran ciertas orientaciones particulares; en muchos casos, estos sitios están coordinados con puntos específicos del paisaje: con cerros y otros elementos naturales, o también con marcadores artificiales en forma de símbolos 0 de edificios construidos en estos lugares. Afirma Broda que se han hecho mediciones de muchos sitios, lo cual permite concluir que un gran número de estas orientaciones estaban diseñadas intencionalmente para marcar la dirección de la salida 0 la puesta del Sol y/o de las estrellas o constelaciones en determinadas fechas. El testimonio arqueológico plasmado en las orientaciones comprueba que se observaban determinados fenómenos astronómicos sobre el horizonte.

Sánchez P. Domingo, (2000), (2002), (2008), (2010). En su análisis sobre El símbolo de Venus en el Arte Rupestre de América. Menciona que el símbolo creado por los Mayas para representar al planeta Venus, el cual consiste en una cruz equidistante con un pequeño rombo o cruz en el centro, ha sido hallado, con 
la forma de una cruz equidistante pero bordeada, en manifestaciones rupestres tanto en el Suroeste de Norteamérica y México, vinculadas mitológicamente a la "estrella Venus", y también se halla en el Caribe y Venezuela, repitiéndose en el arte rupestre de Perú, Chile y Norte de Argentina. Resalta que al comparar los simboles venezolanos con el símbolo aceptado para Venus en Meso América, presentan parecidos innegables. Demuestra que el diseño de la cruz bordeada, resulta común en áreas muy vastas a saber: en el Sur Oeste de Norteamérica, en México (fuera del área Maya), en el Caribe, Venezuela y ahora en Perú, Chile y en el norte de Argentina. Menciona que no ha tenido aún información procedente de Brasil, Colombia, Ecuador, Bolivia, ni otros países de Centro América lo cual no excluye que pueda existir dicho diseño en el arte rupestre de estos países.

Sánchez P. Domingo, (2008), también reconoce que el hallazgo de similitudes morfológicas, en manifestaciones de arte rupestre en lugares muy distantes, no implica necesariamente un proceso de difusión, aclara que esta investigación trata de una hipótesis de trabajo, habida cuenta que, no estando presentes los autores de dichas manifestaciones, sólo queda a los espectadores del arte rupestre, intentar hallar una o varias aproximaciones al posible significado.

Sánchez P. Domingo, (2000), hace una propuesta metodológica para analizar el arte rupestre, desde el punto de vista de la Astronomía, en el estudio de las antiguas astronomías, las cuales son tratadas en la nueva rama de esta ciencia, conocida como Arqueoastronomía y se aplica a las etnias de todo el mundo. Esta propuesta del investigador Sánchez, consiste en crear dos nuevos conceptos básicos aplicados al arte rupestre, que parten de la búsqueda de petroglifos o pinturas rupestres, partiendo de su morfología, proponiendo una nueva clasificación de los mismos en: Astromorfo(s) Astromorfo del latin "Astrum: astro, estrella, constelación. Con la forma de un cuerpo astronómico.]Morfo del griego Morphé que significa forma y Meteomorfo(s) Meteomorfo del griego Meteöron: cualquier fenómeno o apariencia en la atmósfera.

En el ambiente académico las evidencias de obras humanas hechas en, o sobre piedra; conocidas como arte rupestre, son bastante frecuentes por varias zonas o regiones del mundo, de ahí que su existencia en Honduras no es nada nuevo, es más, según varios autores, aparecen en varios departamentos del país (Scheffler 2000 y 2004). (Juárez y Figueroa 2004, Rodríguez Mota et al 2005), aunque en la zona sur no se han analizado hasta ahora, como si, se ha hecho en los departamentos del norte, este y oeste del país.

Las investigaciones de reconocimiento de arte rupestre en el material arqueológico en Honduras, salvo raras excepciones; han sido superficiales, básica- 
mente se trata de reconocimiento o rescate, sin estudios sistemáticos profundos sobre todo en cuanto a arte Rupestre nos compete. Las descripciones arqueológicas más fructíferas para recurrir a la historia vienen de Doris Stone en (1957) y las referencias de Reyes Mazzoni (1977), Vito Veliz (1983) y las descripciones geográficas de Pineda Portillo (1997). (Rodríguez Mota et al 2005). Entre los últimos proyectos de investigación de arte rupestre mas completos en Honduras tenemos los de Juárez y Figueroa 2004 y Rodríguez Mota et al 2005.

En la zona sur de Honduras y probablemente en otras regiones del continente americano, los campesinos hablan de la observación de un astro brillante en el horizonte durante la madrugada y en horas del atardecer, y en ciertos periodos del año; astronómicamente se sabe que se trata del planeta Venus. Este planeta, de brillo aparente muy grande, destaca en el firmamento, tanto en su aparición matutina, como "estrella de la mañana" y en la vespertina, reconocido como "lucero de la tarde".

En el caso concreto de la sociedad Maya, Venus fue muy observado, también existen numerosas referencias de que otros grupos étnicos aborígenes del norte y sur de América y la región del Caribe, así como en casi todo el mundo, a Venus se le estudio incluso y de forma detallada, en sus desplazamientos orbitales Evidencias del reconocimiento detallado del planeta Venus, se encuentran en la cultura Inca, Aymaras, Chibchas, en las etnias de la Patagonia, en las del Brasil, las Guayanas y el Caribe. Como también se encuentran en las etnias del territorio venezolano, se reconoce al planeta, después del Sol, la Luna, el cúmulo de las Pléyades y las estrellas.

La Civilización Maya logro identificar a Venus con un símbolo específico, el cual se halla repetidas varias veces en el Código de Dresde y en algunas ocasiones en los Códices de Madrid, París, Borgia y más recientemente en el Grolier. Además de sus avanzados conocimientos astronomicos los mayas desarrollaron su influencia en las etnias vecinas, por la vía del intercambio de productos no solo en la región mesoamericana, sino también en el resto de Centroamérica.

\section{Objetivo}

Analizar sitios de Arte rupestre en los departamentos de Valle y Choluteca de la zona sur de Honduras, para determinar su posible contenido de información Arqueoastronómica. 


\section{Metodología}

La presente investigación será de tipo cualitativo, con enfoque descriptivo y con temporalidad transversal. Se realizará una descripción y análisis del entorno general de los sitios arqueológicos con arte rupestre, luego de la descripción y el análisis fotográfico de los posibles elementos con características astronómicas presentes en las rocas, ya sean estos pictóricos o petrograbados.

La profundidad del estudio implicó describir, registrar y analizar las muestras de arte rupestre encontradas en los diferentes sitios y determinar una posible relación astronómica en su diseño. La realización abarco desde el mes de agosto de 2013 a septiembre de 2014, en este periodo se desarrollaron una serie de variables que estructuraron la investigación. Se trabajó con los sitios arqueológicos que presentaron muestras de arte rupestre en el sur de Honduras, especificamente en los departamentos de Choluteca y Valle. La presente investigación es de tipo descriptivo y transversal en la que se realizó una descripción y análisis del entorno general de los sitios, hasta llegar a la descripción y el análisis in situ y fotográfico del arte rupestre con características astronómicas, ya sean estos pictóricos o petrograbados.

La primera parte del trabajo se baso en la revisión bibliográfica; para definir qué se entiende por arte rupestre y sus diferentes variables (tipos de sitios, categoría, técnica, ubicación y relación astronómica de arte rupestre), así como monografías y referencias históricas de la zona de estudio. Entre las instituciones de investigación consultadas se destacan la Biblioteca Central de la UNAH, Colección Hondureña, Hemeroteca Nacional, Archivo Nacional, Biblioteca del IHAH entre otras. También se realizaron entrevistas en campo a habitantes de la zona de estudio e investigadores conocedores del tema. Esta actividad sumada a la información recabada en la visita de campo, nos permitió describir el entorno natural que rodea los sitios arqueológicos e identificar su situación actual y potenciales amenazas.

En la segunda parte se presenta el marco teórico, propio de la investigación del arte rupestre como fuente de información astronómica, haciendo referencia a casos de estudio registrados y publicados al nivel internacional.

En la tercera parte, se exponen las actividades realizadas durante el trabajo de campo, para identificar los sitios arqueológicos y verificar su posible alineamiento con los movimientos aparentes del sol, la luna u otra posición de otro planeta. En esta etapa se tomaron todas las imágenes necesarias de los grabados en la roca, para interpretar la posible representación de elementos astronómicos. 
Se utilizaron fichas de campo para recolectar los códigos de identificación de las unidades territoriales donde se encuentran los sitios con arte rupestre identificados y se registraron las ubicaciones exactas por medio del uso de Sistemas de Posicionamiento Global (GPS). La mejor época en Honduras para los recorridos 0 reconocimientos arqueológicos en el campo, es durante la época seca; esta permite movilidad y visibilidad óptima debido a que la cubierta vegetal está seca y los arbustos tienen poco follaje, facilitándose la movilización y reconocimiento de los restos arqueológicos en la superficie terrestre.

En la cuarta parte se procedió a la elaboración de un banco de imágenes, para la elaboración de la cartografía temática, luego se hizo el respectivo análisis de la información recolectada utilizando el programa o Sistema de Información Geográfica (SIG) Arc Gis versión 9.2. Y para la verificación de posibles alineamientos astronómicos del arte rupestre en determinadas fechas del año se utilizo el programa de simulación astronómica Stellarium. Para el proceso de tratamiento de imágenes y resaltar detalles de arte rupestre en superficies se uso el programa image $j$.

En la quinta parte se realizó una comparación entre las muestras de arte rupestre identificadas en el área de estudio con muestras reconocidas de otras regiones como por ejemplo México, Centro América, El Caribe y Sur América; en procura de expresiones astronómicas análogas. Para ello se recurrió a literatura científica contenida en investigaciones donde se presentan imágenes de petrograbados o pintura rupestre.

\section{Resultados}

Esta investigación permitió obtener la ubicación, descripción y análisis del arte rupestre elaborado por poblamiento antiguo de personas en los departamentos de Choluteca y Valle de la región sur de Honduras (ver figura $N^{\circ} 1$.), este logro viene a facilitar el acceso a información detallada y explicativa del quehacer cultural de los diferentes grupos humanos que se asentaron en estos sitios o que simplemente hayan estado de paso. Además se logro verificar si los diseños del arte rupestre encontrados tienen alguna vinculación astronómica y si se trata de diseños que aparecen en otras regiones del continente americano. También se realizó un análisis de la situación de posibles riesgos a los que se encuentran expuestos cada uno de los sitios, destacando el interés en su protección para beneficio del fortalecimiento cultural en las comunidades donde se encuentra dicho arte y las vecinas. 


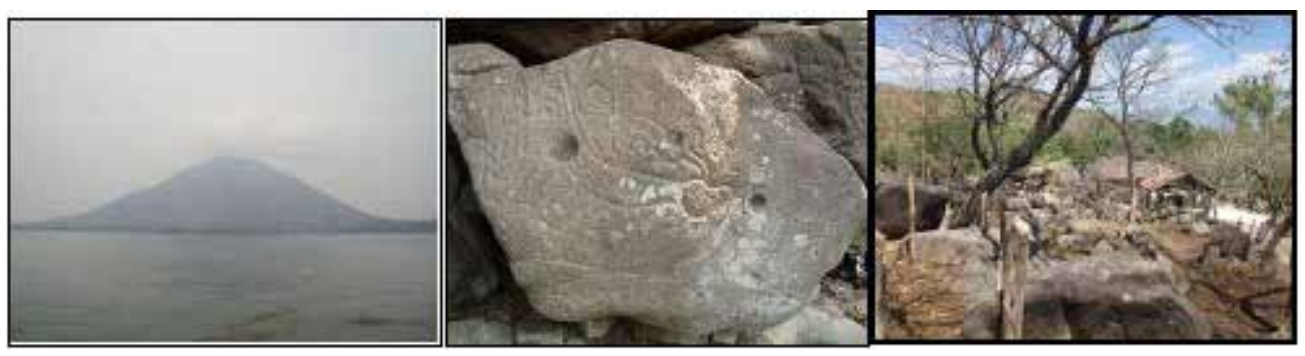

Figura $\mathrm{N}^{\circ}$ 1. Ubicación de sitios de Arte Rupestre en la zona de estudio, Isla del Tigre, en el departamento de Valle (izquierda), y las pinturas (centro)

Las pintadas, Concepción de María. Choluteca (derecha).

\section{Giras de campo para la investigacion in situ del arte rupestre en los departamentos de choluteca y valle.}

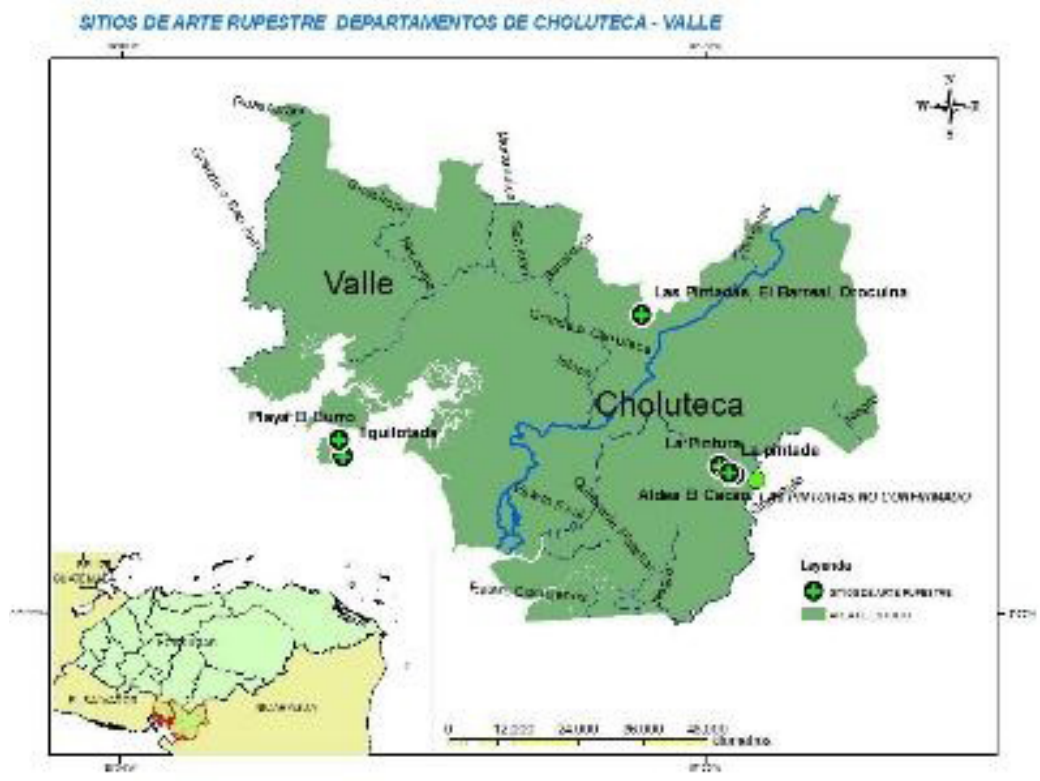

Figura $\mathrm{N}^{\circ}$ 2. Ubicación de sitios de Arte Rupestre en la zona de estudio en los departamentos de Choluteca y Valle.

Se visitaron los siguientes sitios durante la fase de prospección de campo que permitió obtener los datos de análisis de esta investigación: (ver Figura $\mathrm{N}^{\circ} 2$.) 
1-Las Pintadas de Concepción de María, departamento de Choluteca.

2-Las Pinturas de Concepción de María, departamento de Choluteca

3-Playa el Burro y la aldea Tiguilotada, Isla del Tigre.

4-Aldea el Cacao, Concepción de María, Choluteca.

5-La Pintura, Concepción de María. Choluteca

6-Las Pintadas, El Barreal, Orocuina. Choluteca

\section{Base de datos de códigos nacionales de los sitios de arte rupestre en los Departa- mentos de Valle y Choluteca.}

Toda la información documentada ha servido para actualizar la base de datos de sitios de Arte Rupestre en los departamentos de Choluteca y Valle, permitiéndonos documentar su ubicación y unirla a otros atributos relacionados con cada sitio investigado. Se planteo referenciar el departamento y municipio con su respectivo código nacional, el nombre del sitio arqueológico y la clasificación arqueológica según el Instituto Hondureño de Antropología e Historia. ( Ver tabla. $\mathrm{N}^{\circ}$ 1.).

\begin{tabular}{|l|l|l|l|l|l|l|}
\hline No & DEPTO & COD_DEPTO & MUNICIPIO & COD_MUNIC & SITIO ARQUEOLOGICO & CLASIF_ARQ \\
\hline 1 & CHOLUTECA & 06 & CONCEPCION DE MARIA & 0603 & La Pintura & Categoría Especial \\
\hline 2 & CHOLUTECA & 06 & CONCEPCION DE MARIA & 0603 & Las pintadas & Categoría Especial \\
\hline 4 & CHOLUTECA & 06 & CONCEPCION DE MARIA & 0603 & Las Pinturas & Categoria Especial \\
\hline 5 & CHOLUTECA & 06 & CONCEPCION DE MARIA & 0603 & EI Cacao & Categoría Especial \\
\hline 6 & CHOLUTECA & 06 & OROCUINA & 0610 & Las Pintadas & Categoría Especial \\
\hline 7 & VALLE & 17 & Amapala & 1703 & Playa El Burro & Categoría Especial \\
\hline 8 & VALLE & 17 & Amapala & 1703 & Tiguilotada & Categoría Especial \\
\hline
\end{tabular}

Tabla. $N^{\circ} 1$. Base de datos de los sitios con arte rupestre ubicados en el área de estudio. 


\section{Elaboración de mapas temáticos y banco de imágenes.}

Se elaboró la cartografía temática del área de estudio para ubicar los sitios de arte rupestre registrados en campo, por medio de la utilización de un Gps Magellan Mapper. La georreferenciacion de estos sitios permite crear una base de datos apoyándose en los Sistemas de Información Geográfica, algo aún pendiente en Honduras. Pero de mucha utilidad en el estudio, protección y conservación del Patrimonio Cultural.

Por medio del programa Arc Gis, se procedió a colocar las capas de información a utilizar siendo la primera la capa de referencia con la ubicación de los sitios de arte rupestre, luego las capas de país, departamentos, Centroamérica, coberturas, pendientes, modelos de elevación digital, hidrografía, carreteras, poblados, y se calcularon vulnerabilidad a inundaciones y deslizamientos en base a capas previamente tratadas.

Se elaboró mapas de ubicación geográfica de los sitios de arte rupestre en la zona de estudio (departamentos de Valle y Choluteca), vulnerabilidad a inundaciones, deslizamientos y cercanía a centros poblados y carreteras.

Esta información cartográfica apoya la toma de decisiones municipales, regional o para investigación y desarrollo de las áreas de arte rupestre en la zona de estudio, a la vez que promueve su conservación y protección por medio de entidades como el Instituto Hondureño de Antropología e Historia y UNAH.

Para la verificación de posibles alineamientos astronómicos del arte rupestre en determinadas fechas del año, relacionados con los sitios dentro del área de estudio, se utilizó el programa de simulación astronómica Stellarium (ver figura $\mathrm{n}^{\circ}$ 3). Este simulador permite recrear en el tiempo pasado, presente y futuro el aspecto del cielo en los cuatro puntos cardinales del horizonte de una región determinada por su ubicación geográfica. Esto nos permitió hacer una primera aproximación a la observación del cielo por estos grupos culturales primitivos en una fecha aproximada del 900 al 1500 después de Cristo, (este dato cronológico se basa en una estimación de registros arqueológicos para esta zona realizados por los autores en base a investigaciones previas y registros como los de Baudez y Doris Stone). Para el proceso de tratamiento de imágenes y resaltar detalles de arte rupestre en superficies se uso el programa image J, repasando algunas imágenes presentadas en busca de diseños ocultos o resaltar los presentes, sin resultados positivos puesto que del sitio con pinturas rupestres solo se tenían capturas de imagen y las demás muestras correspondían a petroglifos. 

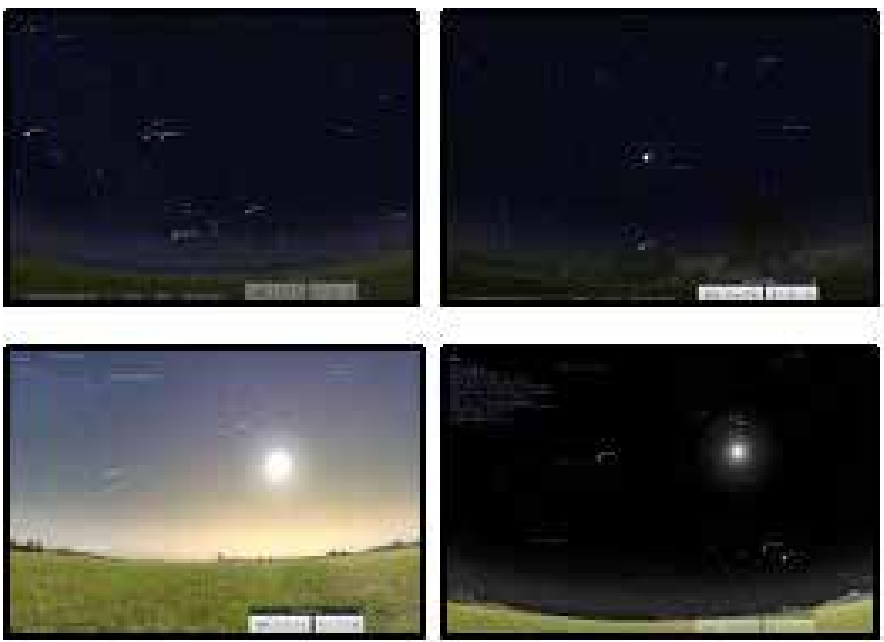

Figura $\mathrm{N}^{\circ} 3$. Detalle de imágenes del programa Stellarium para el sitio de Playa del Burro, Isla de Amapala, con fecha para el año 1500 D.C. Con vista del horizonte este y oeste, con los correspondientes astros visibles.

A continuación se elaboró un banco de imágenes, con los registros de los diseños de arte rupestre encontrados por sitio arqueológico en el área de estudio. Estas imágenes obtenidas en campo, donde resaltan figuras geométricas, zoomorfas, fitomorfas y líneas, sirvieron para hacer una comparación de los diseños encontrados con muestras de arte rupestre ya identificadas con un significado astronómico en estudios previos en otras regiones de América.

Comparación del arte rupestre identificado en el área de estudio con el de otras regiones en méxico, centro américa, el caribe y sur américa.

Los resultados de la comparación de los diseños de arte rupestre de nuestro banco de imágenes, con las muestras de arte rupestre de otras regiones de América arroja resultados sorprendentes en cuanto a la similitud de diseños y nos da una idea de una posible relación astronómica para los diseños de arte rupestre de Honduras en base a analogías de forma y otros. (Ver tablas $\mathrm{N}^{\circ} 2, \mathrm{~N}^{\circ} 3$ y $\mathrm{N}^{\circ} 4$ ). 
Tabla 2. Resumen de evidencia astronómica en el arte rupestre de América.

\begin{tabular}{|l|l|l|l|l|l|}
\hline RESUMEN DE EVIDENCIA ASTRONOMICA EN EL ARTE RUPESTRE DE AMERICA. \\
\hline Licurnique. Peru. Estrellas y Sol & Choapa, Chile Horizonte & \\
\hline
\end{tabular}


Tabla 3. Comparativa de relación simbólica de Venus en el Arte Rupestre de América.

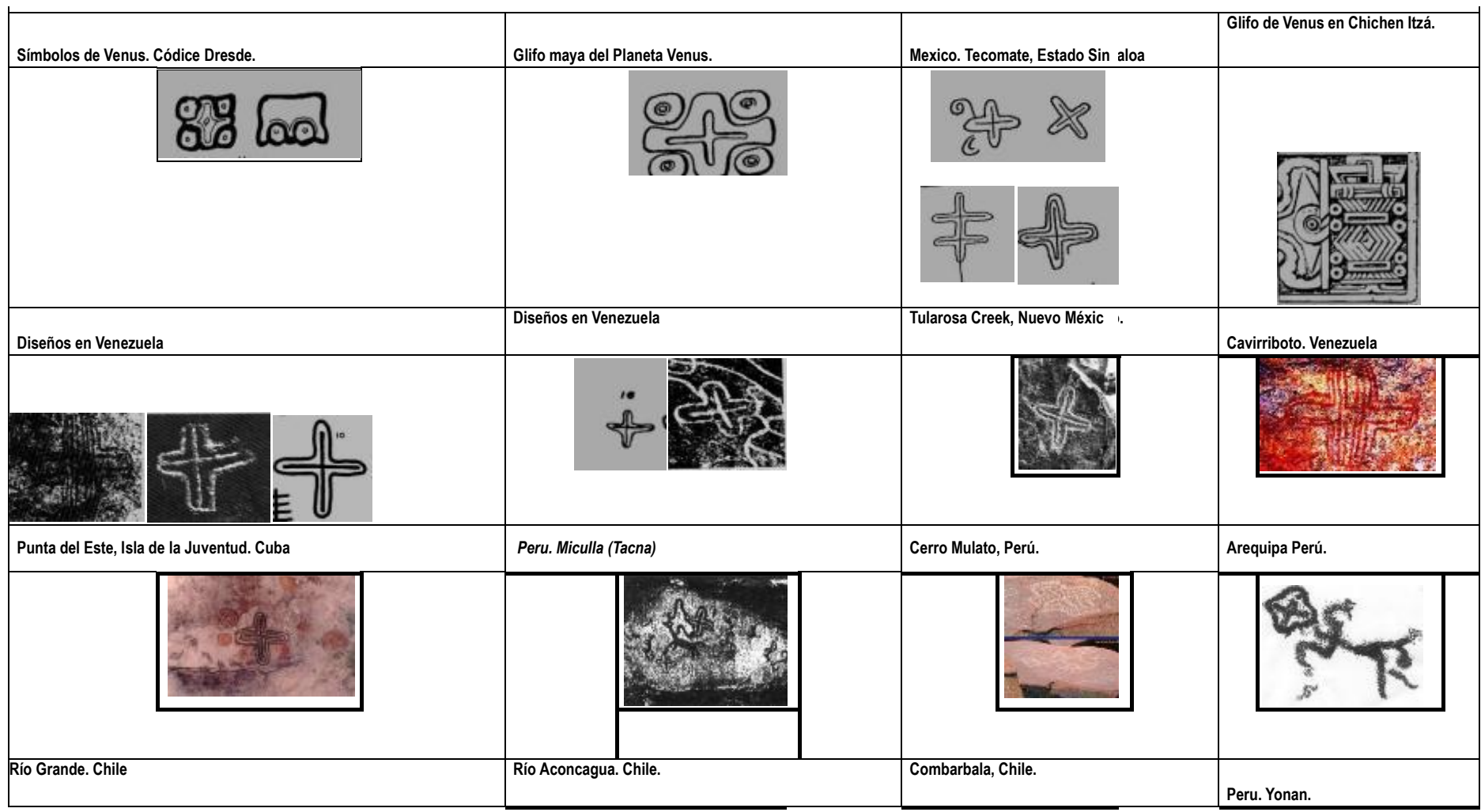


Tabla 4. Interpretación de Diseños de Arte Rupestre según Domingo Sanchez. (2000)

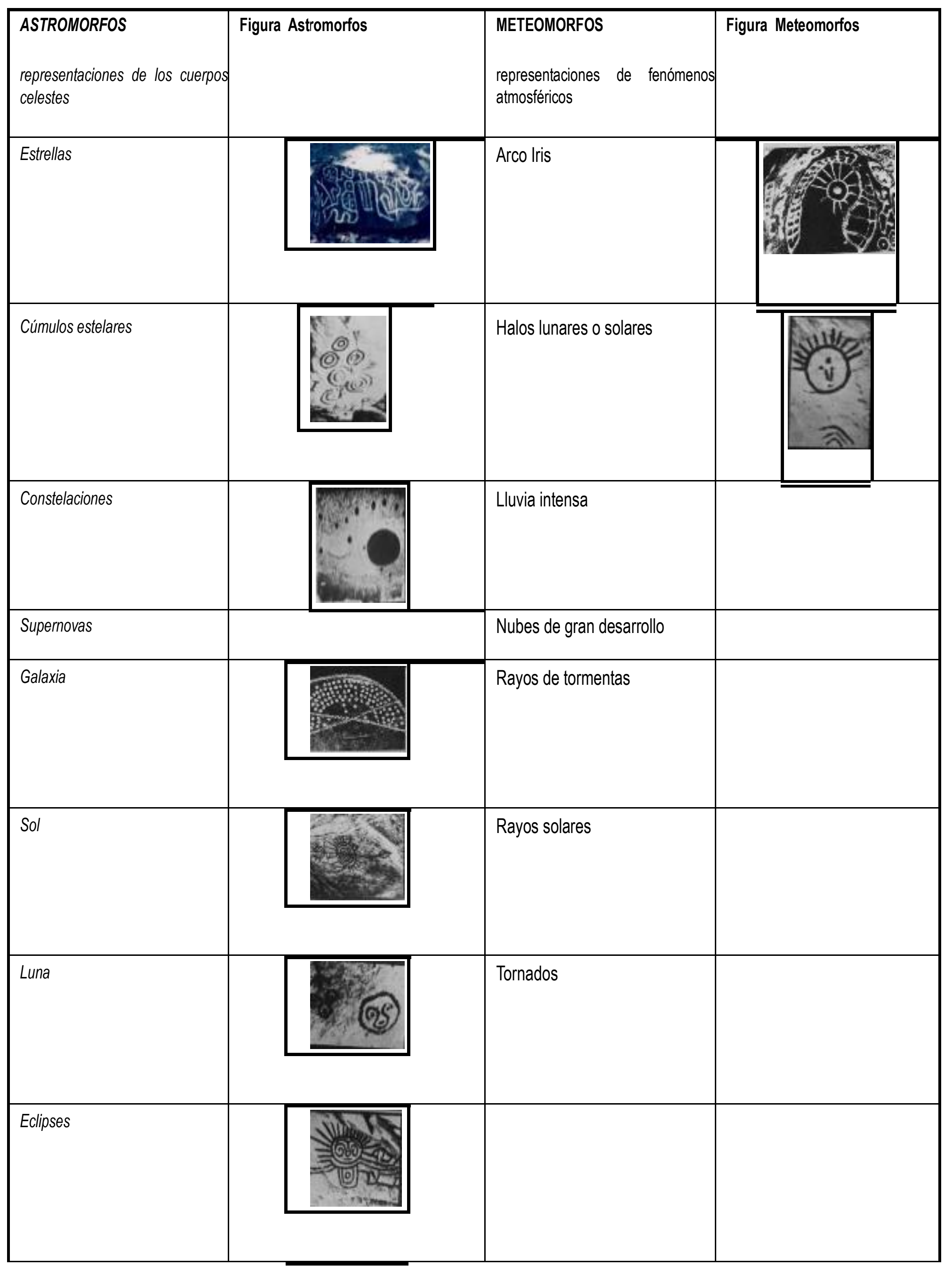

Descripción y análisis del arte rupestre encontrado en los departamentos de Valle y Choluteca.

A continuación se presenta una descripción y análisis de los sitios de Arte Rupestre de los departamentos de Valle y Choluteca, describiéndose por sitio estudiado las características de la imagen numerada, el tipo, técnica de elaboración, técnica en petrograbados, la ubicación del diseño y su posible relación astronómica identificada en base a la comparación con los diseños encontrados en investigaciones previas ya presentadas de otras regiones de América. (ver tablas $\mathrm{N}^{\circ} 5-11$ ). 
Sitio: Aldea La Pintada, Municipio de Concepción de María, Choluteca.

Tabla 5. Tipología del arte rupestre que aparece en Aldea La Pintada, Municipio de Concepción de María, Choluteca.

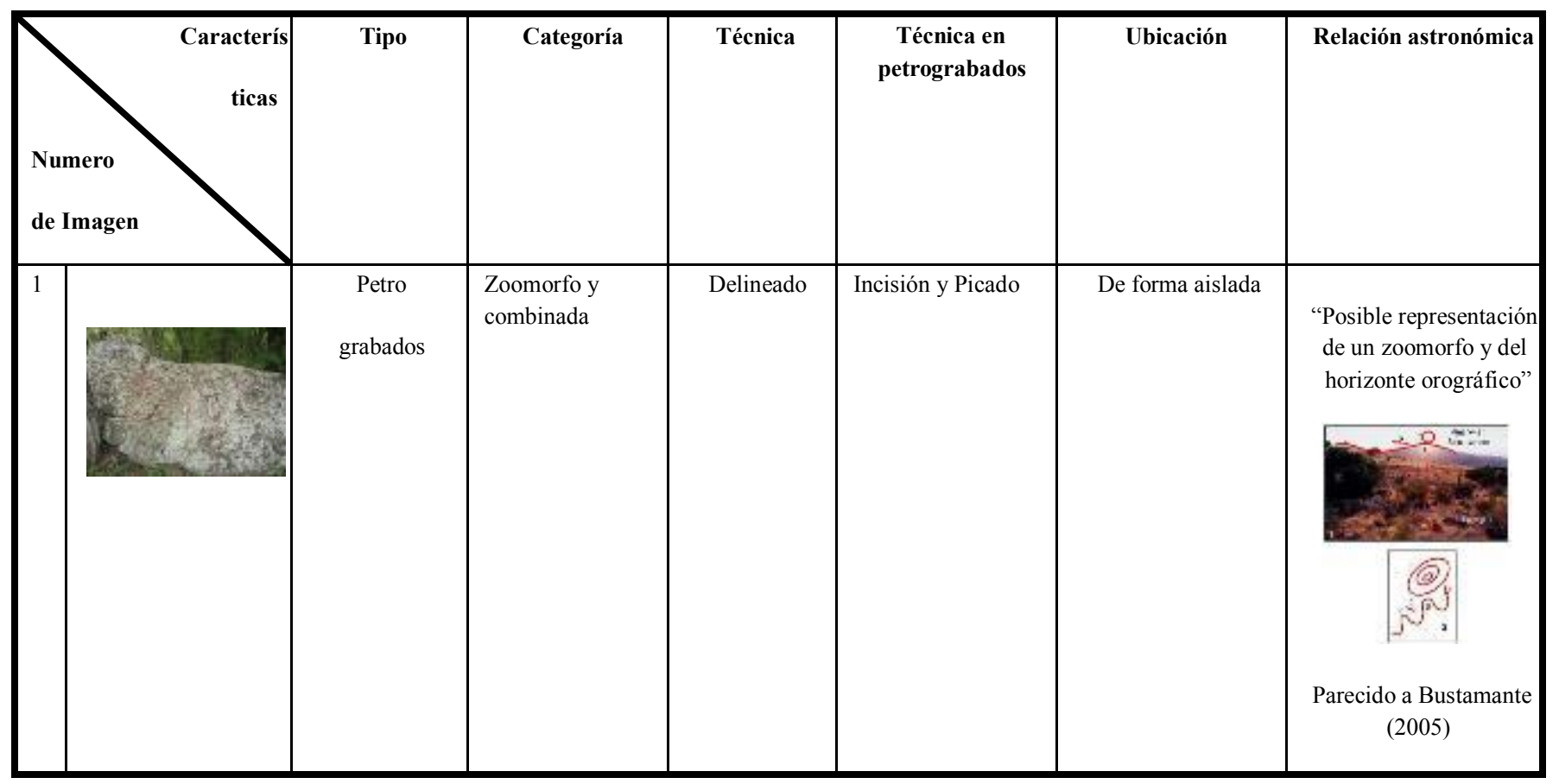


Sitio: Las Pintadas, aldea el Barreal, Orocuina, Choluteca.

Tabla 6 . Tipología del arte rupestre que aparece en el sitio Las Pintadas, aldea el Barreal, Orocuina Choluteca

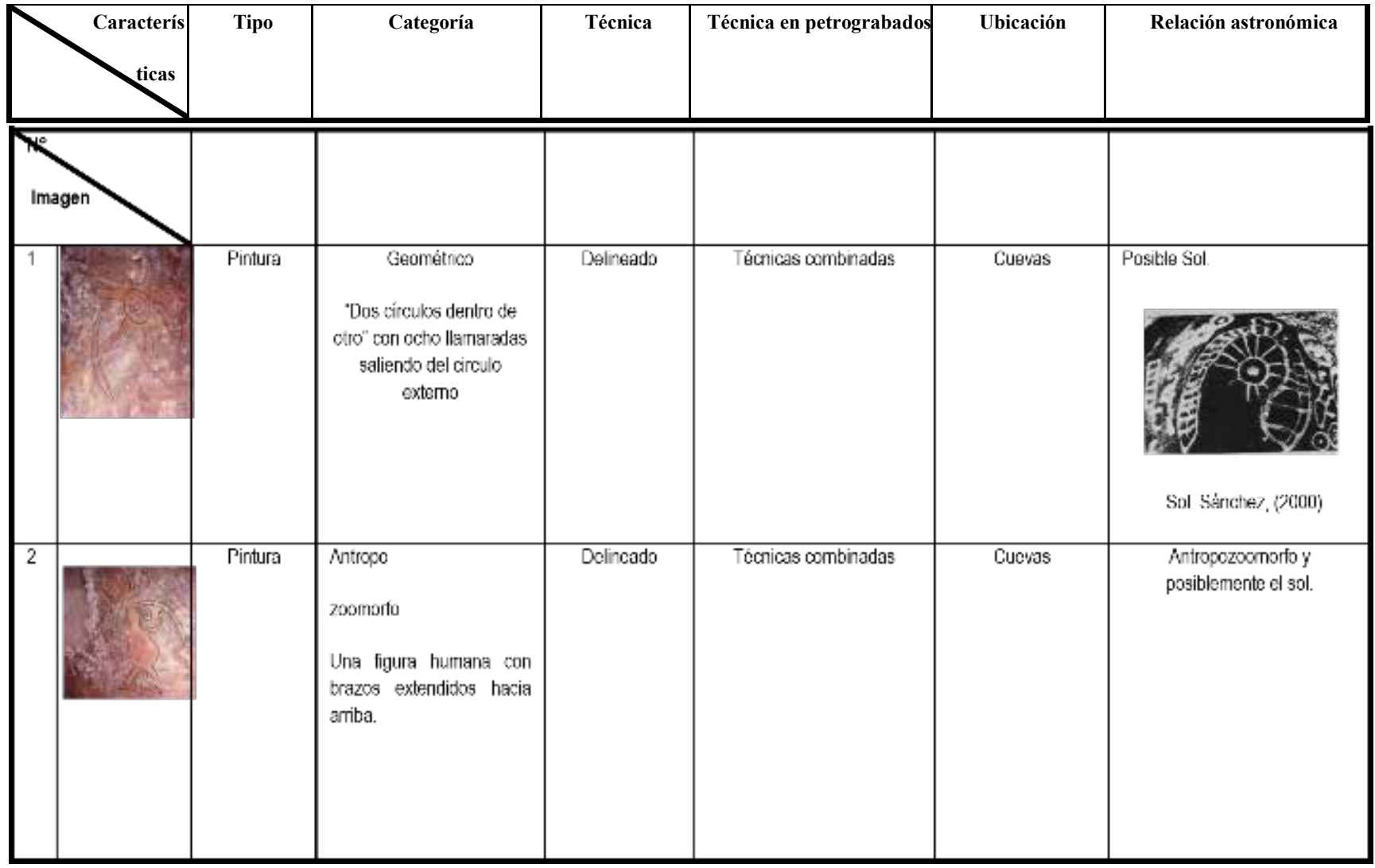


Sitio Las Pintadas. Concepción de María, Choluteca.

Tabla 7. Tipología del arte rupestre que aparece en el Sitio Las Pintadas. Concepción de María, Choluteca.

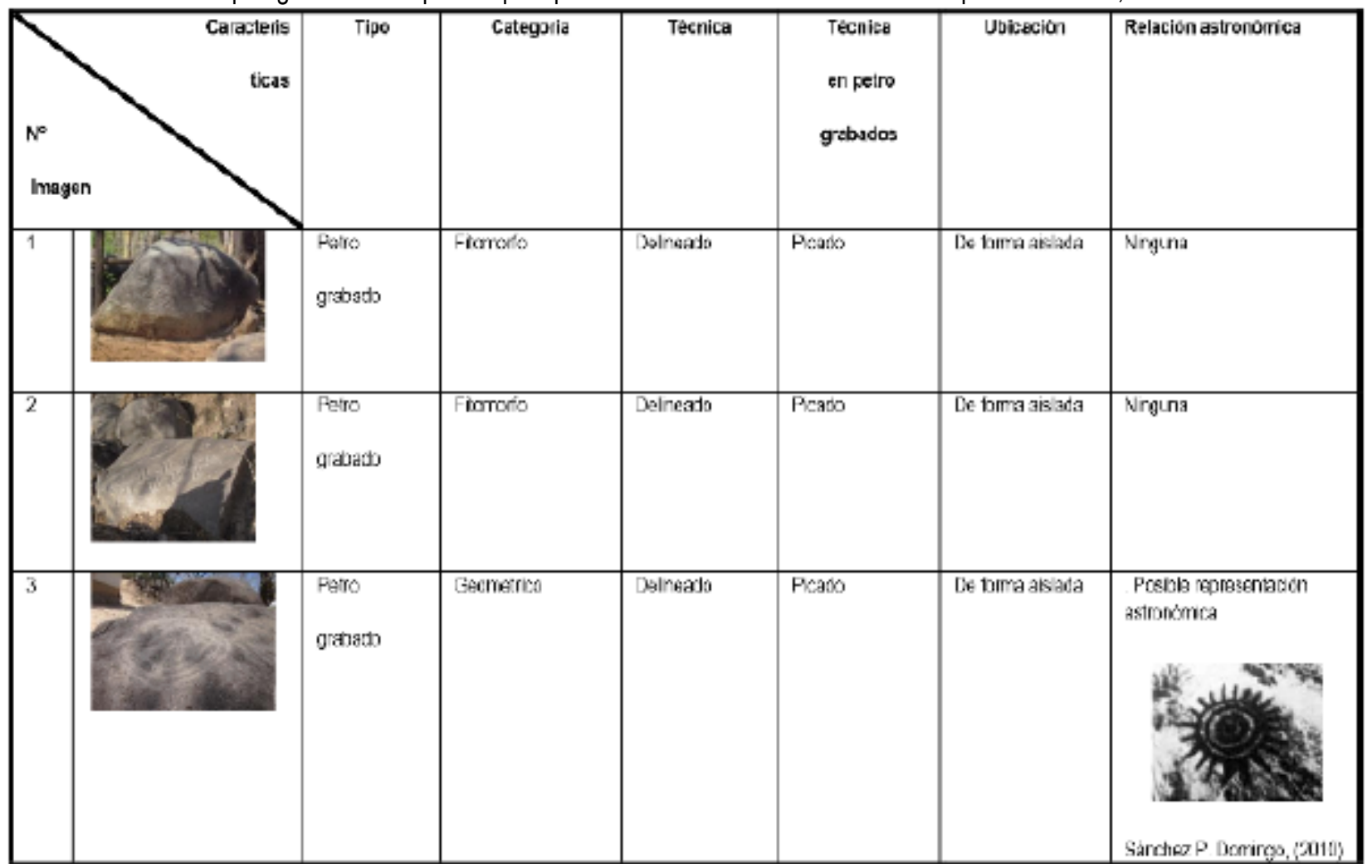




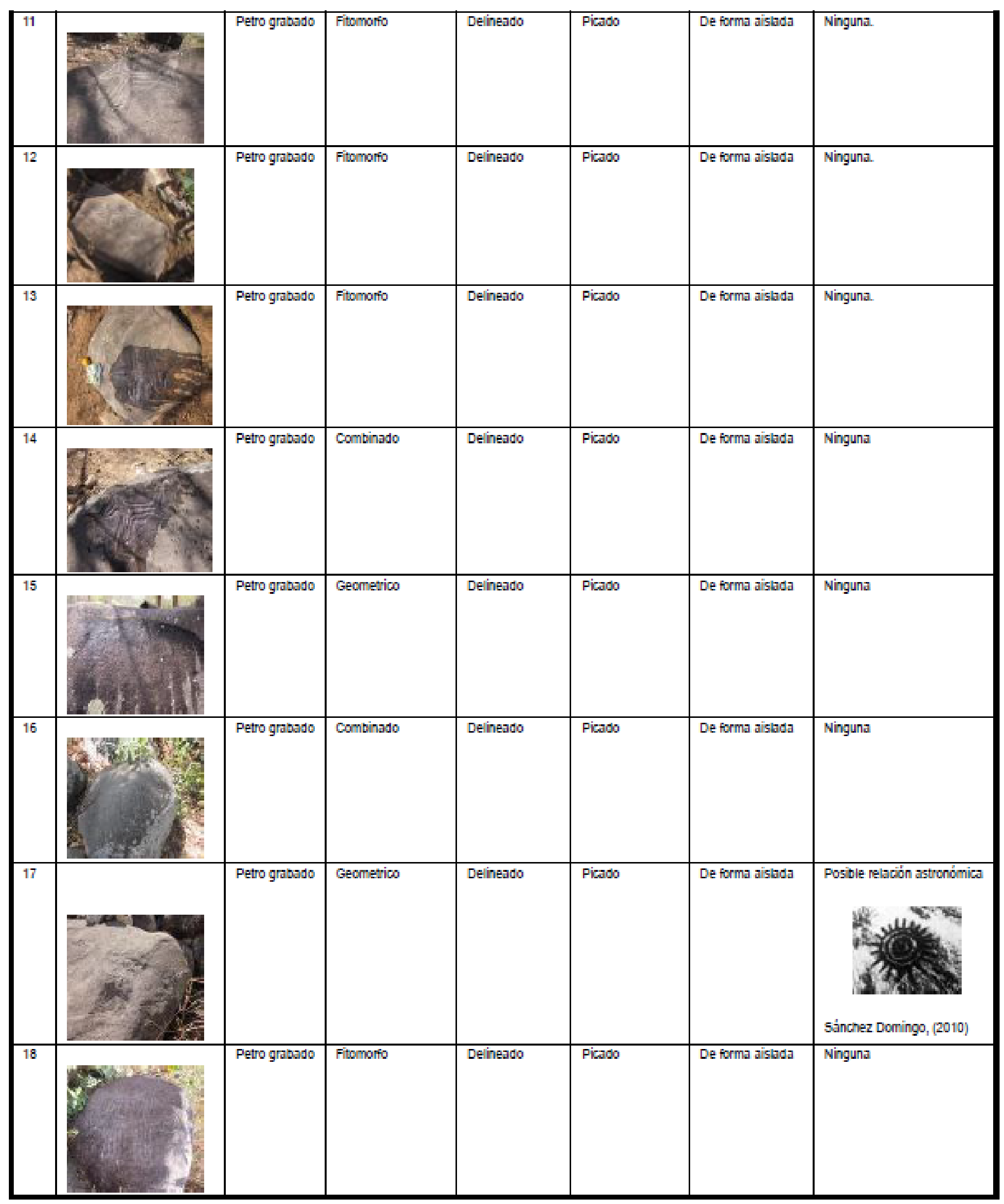




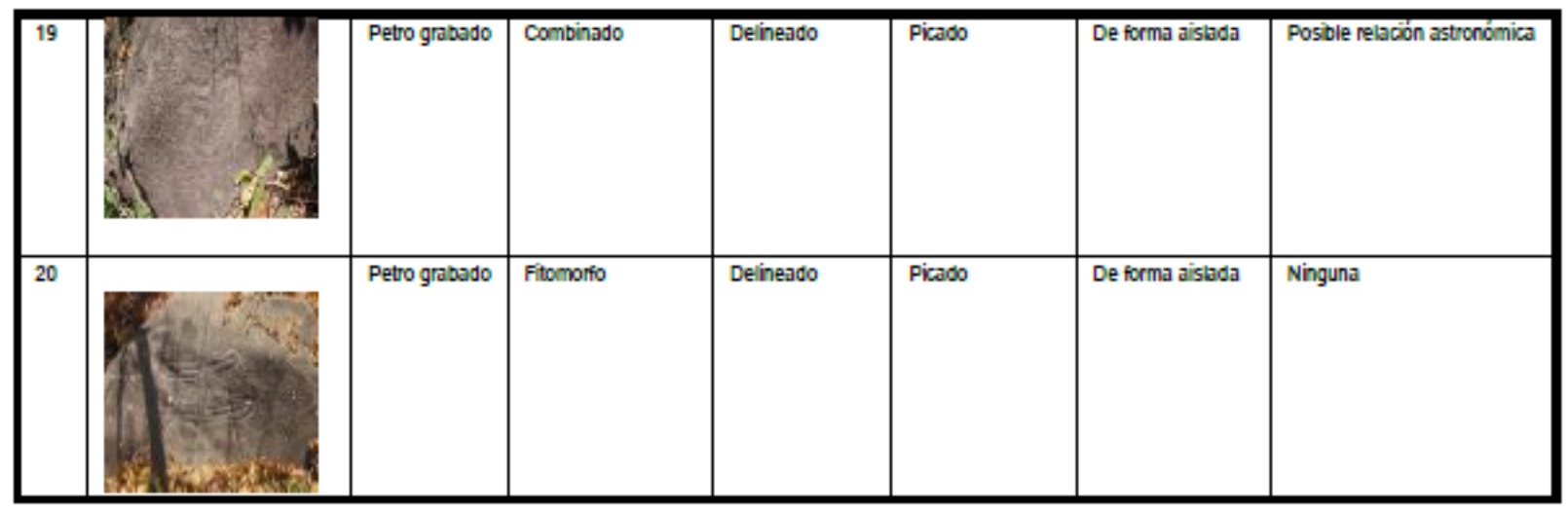


Sitio: Aldea El Cacao, Municipio de Concepción de María, Choluteca.

Tabla 8. Tipología del arte rupestre que aparece en el Sitio Aldea El Cacao, Municipio de Concepción de María, Choluteca.

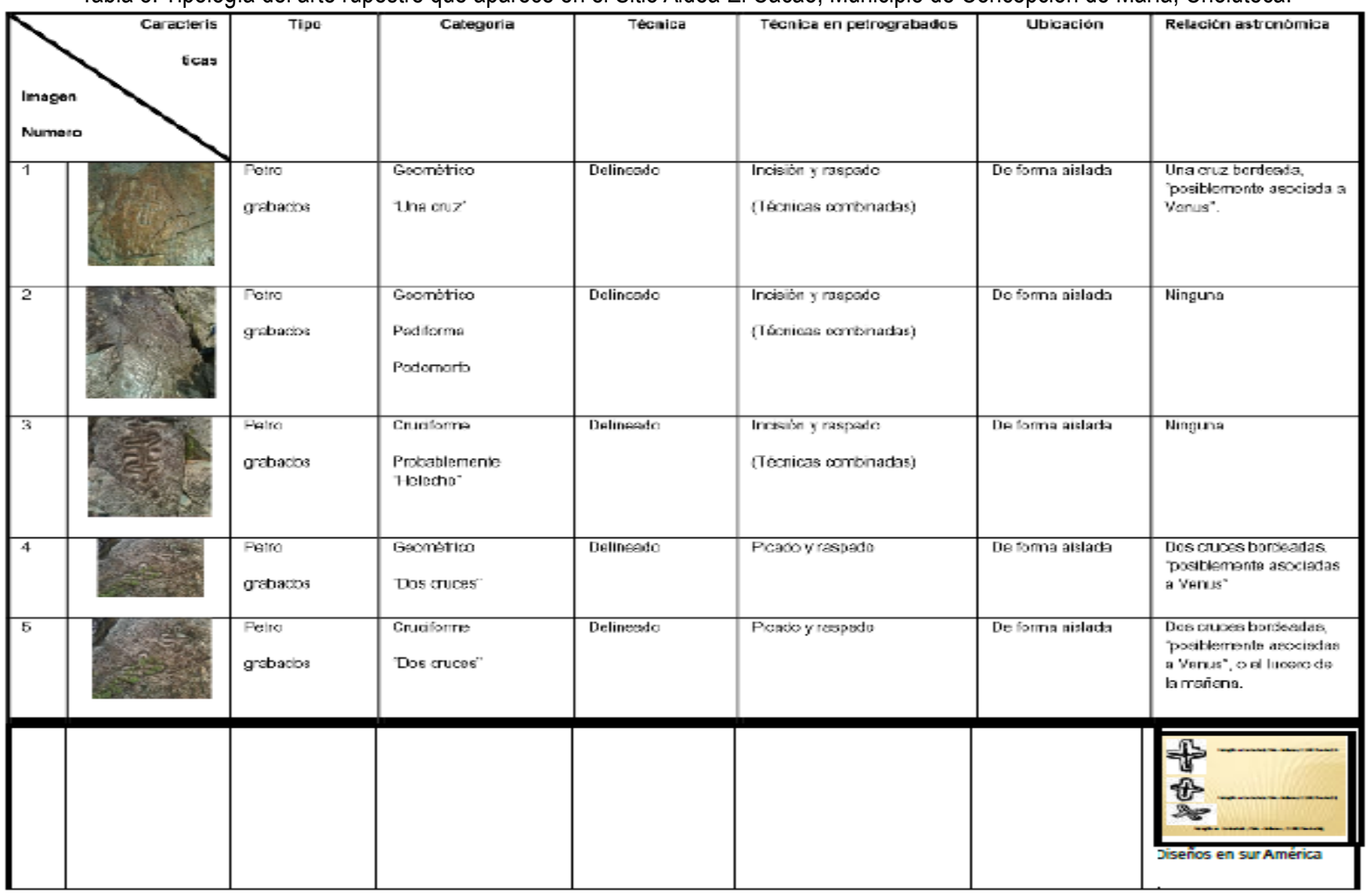




\begin{tabular}{|c|c|c|c|c|c|c|}
\hline 8 & $\begin{array}{l}\text { Petro } \\
\text { grabados }\end{array}$ & Mutiforme & Delineado & Picado y raspado & De forma aislada & Ninguna \\
\hline 9 & $\begin{array}{l}\text { Petro } \\
\text { grabados }\end{array}$ & $\begin{array}{l}\text { Geométrico } \\
\text { "Letra } \mathrm{H}^{\prime}\end{array}$ & Delineado & Picado y raspado & De forma aistada & Ninguna \\
\hline 10 & $\begin{array}{l}\text { Petro } \\
\text { grabados }\end{array}$ & $\begin{array}{l}\text { Geométrico } \\
\text { "Multiforme" }\end{array}$ & Delineado & Picado y raspado & De forma aistada & $\begin{array}{ll}\text { Posible } & \text { relación } \\
\text { astronómica } & \end{array}$ \\
\hline 11 & $\begin{array}{l}\text { Petro } \\
\text { grabados }\end{array}$ & $\begin{array}{l}\text { Fihomorio } \\
\text { Probablemente } \\
\text { "Helecho" }\end{array}$ & Delineado & Picado y raspado & De forma aistada & $\begin{array}{l}\text { Esbozos de la cruz doble } \\
\text { bordeada. }\end{array}$ \\
\hline 13 & $\begin{array}{l}\text { Petro } \\
\text { grabados }\end{array}$ & $\begin{array}{l}\text { Geométrico } \\
\text { "Dos cruces" }\end{array}$ & Delineado & Picado y raspado & De forma aistada & $\begin{array}{l}\text { Dos cauces bordeadas } \\
\text { posible relación con } \\
\text { venus }\end{array}$ \\
\hline
\end{tabular}


Sitio: La Piedra rayada, Aldea Tiguilotada, Isla El Tigre, Municipio de Amapala, Valle.

Tabla 9. Tipología del arte rupestre que aparece en el Sitio La Piedra rayada, Aldea Tiguilotada, Isla El Tigre, Municipio de Amapala, Valle.

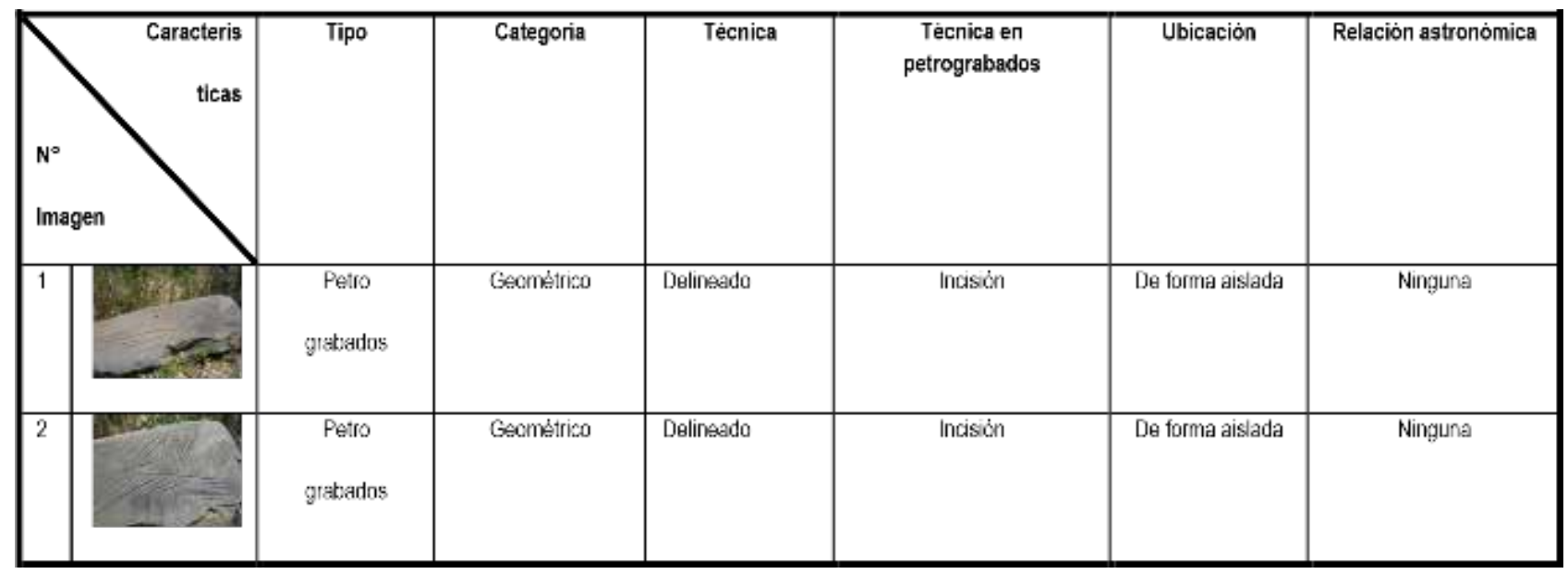


Sitio: Playa El Burro, Isla El Tigre, Municipio de Amapala, Valle.

Tabla 10. Tipología del arte rupestre que aparece en el Sitio Playa El Burro, Isla El Tigre, Municipio de Amapala, Valle.

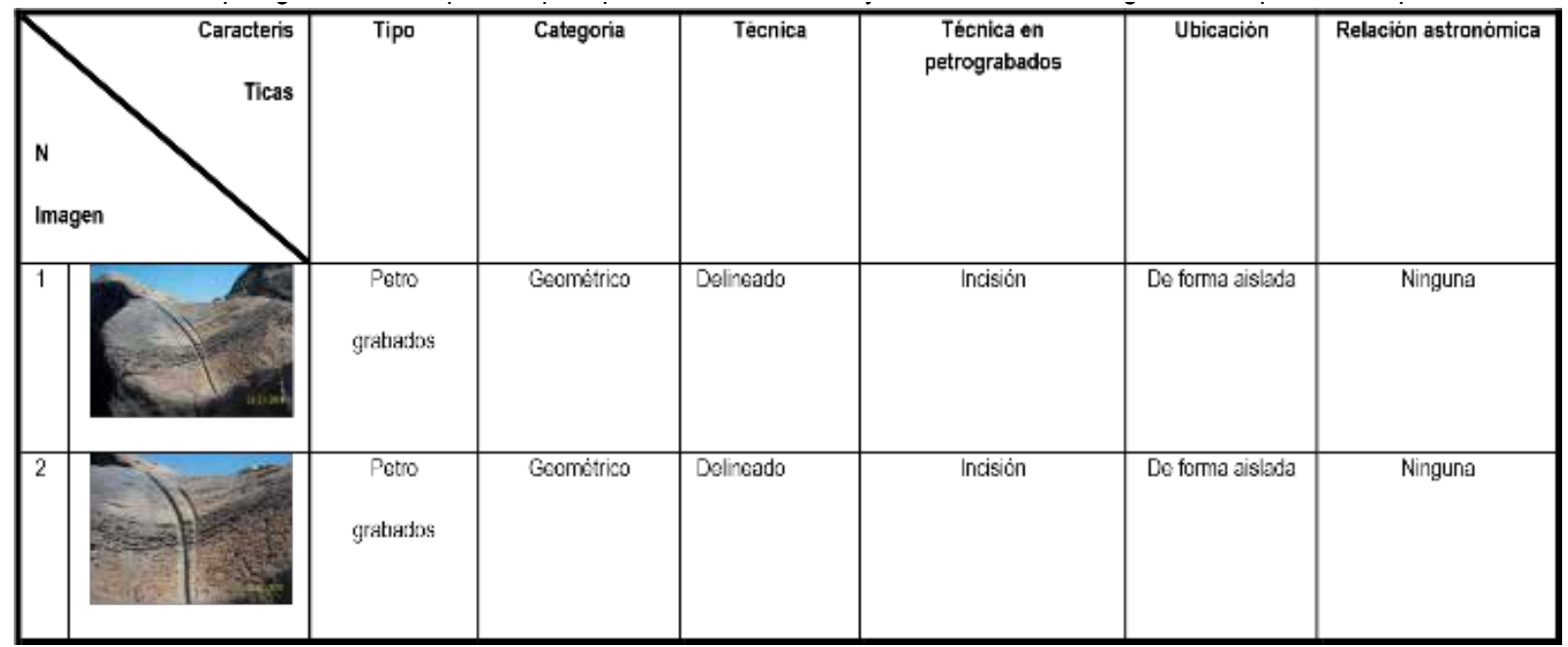


Tabla 11. Imágenes de los sitios estudiados

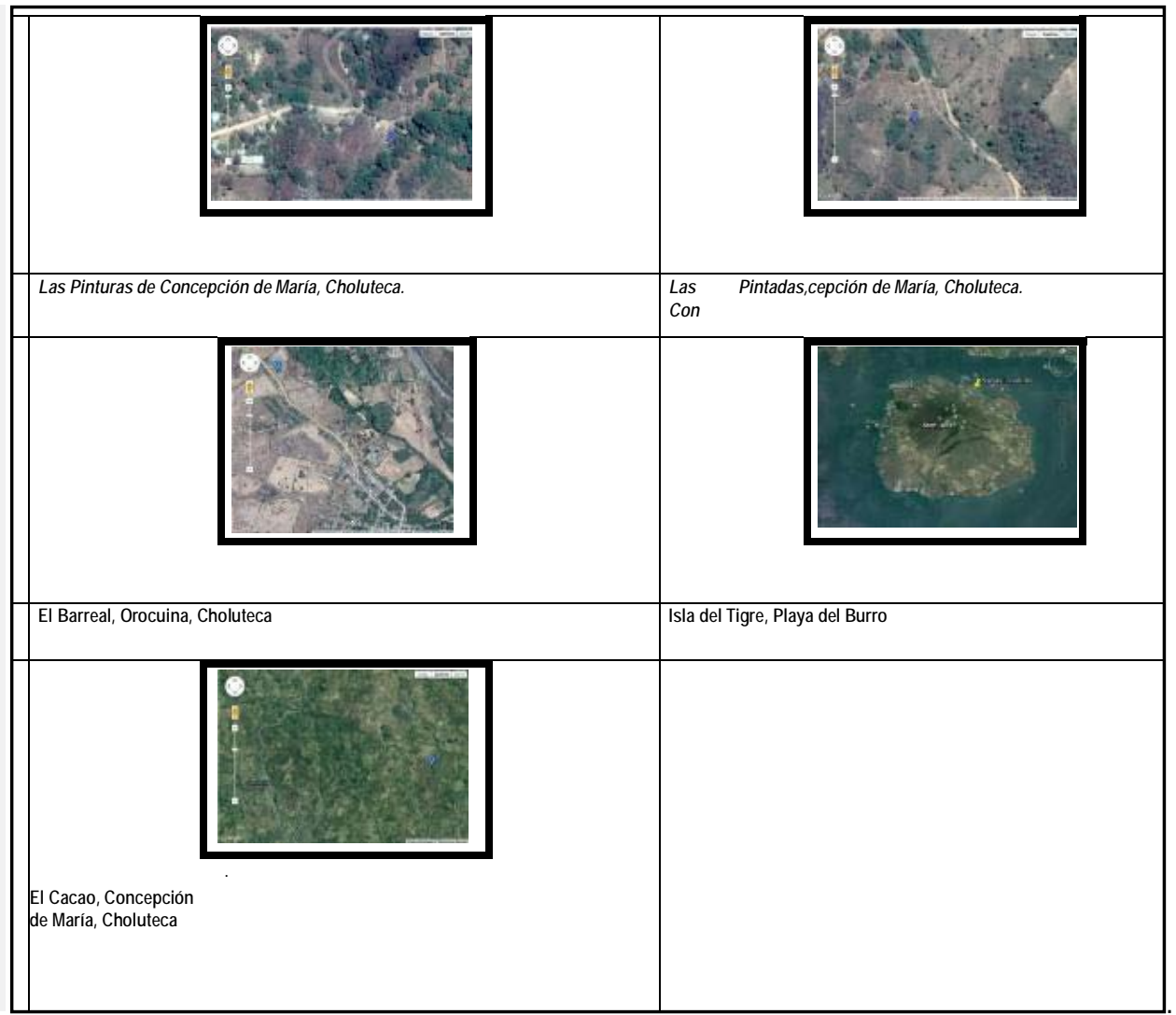


Por último se realizó cartografía temática para los sitios de Arte Rupestre departamentos de Choluteca y Valle, relacionada con vulnerabilidad a inundaciones y deslizamientos.

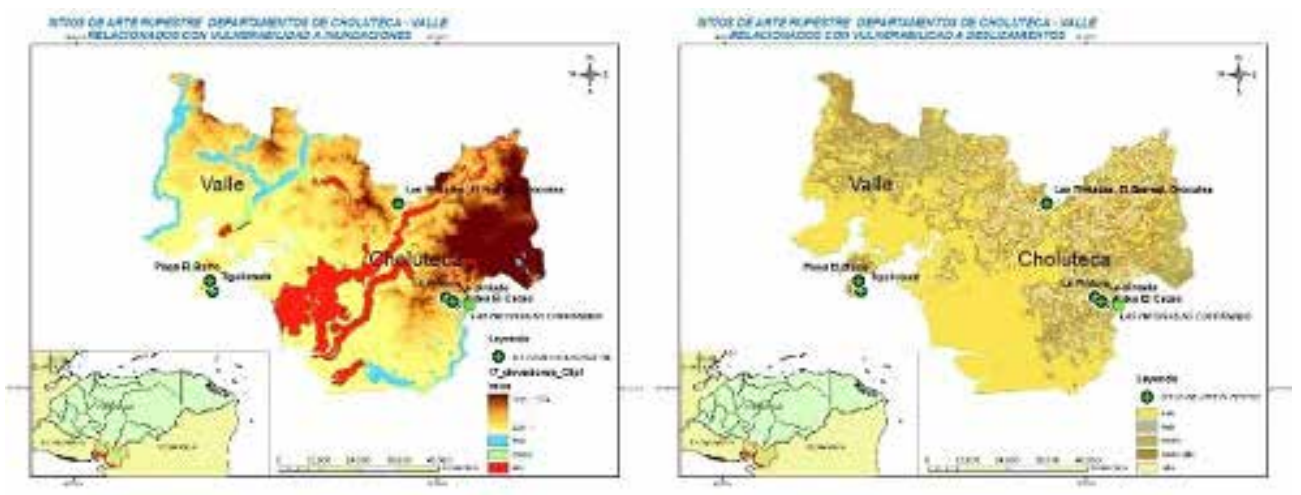

Figura $\mathrm{N}^{\circ} 4$. Mapas de sitios de Arte Rupestre departamento de Choluteca y Valle, relacionados con Vulnerabilidad a Inundaciones (Izquierda) y con Vulnerabilidad a deslizamientos (derecha).

\section{Conclusiones}

Se ha identificado y estudiado sitios de arte Rupestre en la zona sur de Honduras, analizando la información de campo y laboratorio obtenida, comparando diseños de petroglifos y pintura para determinar evidencia de observaciones astronómicas en estos sitios por parte de los grupos culturales que los habitaron y posibles alineamientos de sitios arqueológicos con astros.

El arte rupestre que elaboraron los antepasados pobladores del área de estudio, se relaciona con sus actividades de vida diaria, principalmente asociadas a actos rituales y de observación del cielo, en el caso de los sitios identificados en el departamento de Choluteca y Valle presentan una fuerte asociación con observaciones astronómicas; aspecto que constituye un elemento fundamental para la astronomía cultural en Honduras. Esta investigación permite llenar vacios de información científica en la zona sur de Honduras, dando a conocer datos culturales de nuestros ancestros, registrados en piedra y los sitios que los contienen, aunque siempre es necesario el desarrollo de estudios étnicos para la correcta y completa identificación de los diferentes grupos de humanos que poblaron el área de estudio y consecuentemente la reconstrucción del pasado prehispánico de Honduras.

Estos son resultados preliminares a la puesta en marcha de un proyecto de investigación innovador en Honduras donde se pone a prueba la metodología de 
investigación para el estudio arqueoastronómico en el arte rupestre. Cada uno de los sitios con arte rupestre estudiados en los departamentos de Valle y Choluteca han demostrado su importancia en la historia de Honduras, específicamente en lo que respecta a la etapa posiblemente precolombina, lo que hace necesario un estudio mas individualizado para cada uno de los sitios, de tal forma que se pueda describir el escenario cultural en el que fueron elaborados; fortaleciendo de esta forma la ciencia histórica y el campo científico de la astronomía cultural aplicada al país.

Cada uno de los sitios estudiados en esta investigación aparecen poco conocidos por las comunidades aledañas y por las autoridades de los gobiernos locales, lo que hace necesario la planificación de experiencias de divulgación en las comunidades vecinas para que se adueñen de su patrimonio cultural, con el propósito que puedan ser las depositarias y protectoras del mismo, para beneficio de las generaciones presentes y futuras.

Debido al importante aporte que hace el arte rupestre en la interpretación de las primeras poblaciones que se instalaron en estos territorios es urgente la incorporación del tema del arte rupestre en Honduras, en el currículo nacional básico (CNB) de la Educación Básica que se desarrolla en los diferentes centros educativos del país.

Considerando la similitud de los glifos identificados en los diferentes sitios con arte rupestre en los departamentos de Valle y Choluteca, con otros glifos que aparecen en la región Centroamericana, Mesoamérica, América Insular y del Sur; se puede expresar que los pobladores que realizaron el mismo tenían influencias 0 provenían de estas regiones; condición que permite pensar que el área de estudio funciono como vía de paso para varios grupos étnicos que dejaron su arte en la zona.

\section{Bibliografía}

- Andrade G. José Fernando. 2003. Registro sistemático de yacimientos rupestres en el municipio de Timaná, Huila. En Rupestreweb, http://www.rupestreweb.info/huila.html (Consulta mayo 2014)

- Bednarik, R.G. 2004. Arte rupestre, tafonomía y epistemología. En Rupestreweb, http://rupestreweb.tripod.com/bednarik2.html (Consulta mayo 2014) 
- Bustamante, Patricio.2005. Entorno: obras rupestres, paisaje y astronomía en El Choapa, Chile. En Rupestreweb, http://rupestreweb.tripod.com/elmauro.html (Consulta mayo 2014)

- Broda, Johanna. (1997). Arqueoastronomía y Desarrollo de las Ciencias en el México. Astronomía Moderna e Historia de la Ciencia. En: http://es.scribd.com/ doc/150343524/Astronomia-Historia-de-La-Astronomia-en-Mexico. (Consulta mayo, 2014).

- Gonzales de la Fuente, Héctor. "Arte rupestre en Nuevo León, México -Galería fotográfica-". En Rupestreweb, http://www.rupestreweb.info/gonzalez.html (Consulta mayo 2014)

- González Ojeda, Diego. 2008.Un acercamiento al arte rupestre de Loja, Ecuador.

- En Rupestre/web, http://www.rupestreweb.info/loja.html. (Consulta abril 2014)

- Guevara, Luisa Merari. 2012. Tipos de Arte Rupestre en Honduras. Red Española de Historia y Arqueología. (Consultado en www.historiayarqueologia.com).

- Hart, Laura. 2010. Secuencias gráficas. Un recurso común entre el arte prehistórico y el contemporáneo. En Rupestreweb, http://www.rupestreweb.info/arteprehistorico.html (Consulta mayo 2014)

- Jaimes R. Anderson. 2010. Los Mojanes o Chamanes protagonistas y autores de los petroglifos tachirenses. En Rupestreweb, http://www.rupestreweb.info/ mojanes.html. (Consulta febrero 2014).

- Martinez C. Diego. 2000 / 2004.Sitios rupestres en Ramiriquí (Boyacá). En Rupestreweb, http://www.rupestreweb.info/ramiriqui.html (Consulta mayo 2014)

- Martínez Celis, Diego y Álvaro Botiva Contreras. 2004. Adaptación del texto y gráficas originales del Manual de arte rupestre Cundinamarca. Gobernación de Cundinamarca-ICANH, Bogotá. 
- Mckittrick, Alison. 2003 Arte rupestre en Honduras. En: Arte Rupestre de México Oriental y Centro América. Martin Kunne and Matthias Strecker, editores. Indiana Supplement, (16): 163-181. Gerb. Mann, Berlin, Alemania.

- Mendiola G, Francisco. ARTE RUPESTRE: Epistemología, Estética y Geométrica. . Sus Interrelaciones con la Simetría de la Cultura. Ensayo de explicación sobre algunas ideas centrales de Adolfo Best Maugard y Beatriz Braniff. En Rupestre/web, http://rupestreweb.tripod.com/mendiola2.html. (Consulta abril 2014)

- Reyes Mazzoni, Roberto. 1976 Introducción a la Arqueología de Honduras, 2 tomos. Tegucigalpa, Honduras.

- Rodríguez Mota, Francisco y Figueroa Alejandro J. 2007. Avances significativos en torno al Proyecto de Arte Rupestre (PARUP) del Instituto Hondureño de Antropología e Historia. En Rupestreweb, http://www.rupestreweb.info/parup. html. (Consulta abril 2014)

- Rodríguez Mota, Francisco Manuel, Alejandro Figueroa y Ranferi Juárez. 2005 El arte rupestre de Honduras: Metodología para su estudio, conservación e interpretación. En: Boletín Yaxkin, Vol. XXII, 2003. Órgano interno de difusión del Instituto Hondureño de Antropología e Historia. Tegucigalpa, Honduras

- Rodríguez Mota, Francisco Manuel, Alejandro Figueroa. 2005 Manual Básico de arte rupestre de Honduras. Instituto Hondureño de Antropología e Historia. Tegucigalpa. Honduras

- Sánchez P. Domingo. (2000). LA ASTRONOMIA EN EL ARTE RUPESTRE: UNA PROPUESTA METODOLOGICA. Ciudad Virtual de Antropología y Arqueología En: http://www.antropologia.com.ar html (Consulta mayo 2014)

- Sánchez P. Domingo.2002. El símbolo mesoamericano de Venus en el arte rupestre de Venezuela En Rupestre/web, http://rupestreweb.tripod.com/venus. html (Consulta marzo 2014)

- Sánchez P., Domingo. 2008. El símbolo de Venus en el arte rupestre de Perú, Chile y norte de Argentina. En Rupestreweb, http://rupestreweb.info/venus2. html. (Consulta mayo 2014) 
- Sánchez P., Domingo.2010. Antiguas figuraciones astronómicas en el arte rupestre y la cestería indígena de Venezuela. En Rupestreweb, http://www.rupestreweb.info/figuraciones.html. (Consulta junio 2014).

- Sin autor. Laboratorio astronómico prehispánico en Licurnique. Peru. Consulta en: http://www.andina.com.pe/agencia/noticia-hallan-evidencias-laboratorio-astronomico-prehispanico-complejolicurnique-515639.aspX\#.U9PXXCgz2GQ (Agosto 2014).

- Pineda Portillo, Noé. 1997 Geografía de Honduras. Tercera Edición. Editorial Guaymuras, Tegucigalpa.

- Stone, Doris. 1957 The archaeology of central and southern Honduras. Papers of the Peabody Museum of Archaeology and Ethnology. Vol 49, No. 3. Cambridge, Massachusetts.

- UNESCO. 2008. Arte Rupestre en el Caribe. Hacia una nominación transnacional seriada a la Lista del Patrimonio Mundial de la UNESCO. Nuria Sanz (Ed.).Paris

- Véliz, Vito. 1983 Síntesis histórica de la arqueología en Honduras. Yaxkin, Vol. VI, Nos. 1 y 2: 1-8. Órgano de Divulgación del Instituto Hondureño de Antropología e Historia, Tegucigalpa. 